\title{
Efeitos de EspaÇamentos Entre Linhas, Épocas de ApLiCAÇÃo e Doses de ImazamoX no Manej o de Plantas Daninhas na Cultura DA SOJ A
}

\author{
The Effects of Row Spacing, Application Times and Rates of Imazamox on Weed Management in \\ Soybean Crop
}

MELO, H.B. ${ }^{2}$, FERREIRA, L.R. ${ }^{3}$, SILVA, A.A. ${ }^{3}$, MIRANDA, G.V. ${ }^{3}$, ROCHA, V.S. ${ }^{3}$ e SILVA, C.M.M. ${ }^{2}$

\begin{abstract}
RESUMO - O objetivo deste trabalho foi avaliar os efeitos da combinação de espaçamentos entre linhas e épocas de aplicação e doses do herbicida imazamox sobre o manejo de plantas daninhas na cultura da soja, cultivar UFV-16. O delineamento experimental utilizado foi o de blocos casualizados, em esquema fatorial $2 \times 8$, com quatro repetições. O primeiro fator correspondeu aos espaçamentos entre fileiras (30 e $60 \mathrm{~cm})$, e o segundo, a modos de aplicação: aplicação única de imazamox nas doses de 30 e $40 \mathrm{~g}$ i.a. ha ${ }^{-1}$, nas épocas de pós-emergência antecipada (precoce) ou pós-emergência inicial normalmente recomendada para as aplicações de herbicidas (padrão); aplicação seqüencial de imazamox nas doses de $15+15$ e $20+$ $20 \mathrm{~g}$ i.a. ha- ${ }^{-1}$, sendo a primeira na época precoce e a segunda na época padrão; testemunha com capina; e testemunha sem capina. Nos dois espaçamentos, observou-se predominância da infestação de plantas daninhas do tipo dicotiledôneas. A aplicação de imazamox resultou em um controle muito bom ou ótimo (acima de 81\%) das plantas daninhas avaliadas, independentemente das doses, dos espaçamentos e das épocas de aplicação, apresentando potencial para ser usado no manejo das plantas daninhas na cultura da soja em aplicação única ou seqüencial, na época precoce ou padrão. Não houve influência dos tratamentos sobre altura das plantas, inserção da primeira vagem, peso de 100 sementes e produtividade da cultura.
\end{abstract}

Palavras-chave: controle, pós-emergência precoce, pós-emergência inicial.

\begin{abstract}
The objective of this work was to evaluate the effects of combining crop row spacing with herbicide application times on weed management in soybean, cultivar UFV-16. The experiment was arranged in a randomized block design, with the treatments following a $2 \times 8$ factorial design, with four replications. The first factor corresponded to crop row spacing (30 and $60 \mathrm{~cm}$ ) and the second corresponded to types of application (imazamox rates at 30 and $40 \mathrm{~g}$ a.i. $\mathrm{ha}^{-1}$, sprayed in very early weed post-emergence (very early) and standard early weed post-emergence (standard), imazamox rates $15+15$ and $20+20 \mathrm{~g}$ a.i.ha ${ }^{-1}$, with sequential application at very early and standard weed emergence times; checks weed free and weeded. For both row spacings evaluated, the predominance of dicot type of weeds was observed. Imazomox application provided a very good to excellent weed control, regardless of the doses, crop row spacing and application times, showing a promising use in weed management for soybean crop, single sprayed rate or in sequence, during very early or standard weed postemergence times. There was no influence of the treatments on soybean plant height, first pod insertion, weight of 100 seeds and crop yield.
\end{abstract}

Key words: control, very early post-emergence, standard post-emergence.

1 Recebido para publicação em 6/2/2001 e na forma revisada em 2/7/2001.

2 Mestrandos do Departamento de Fitotecnia da UFV; ${ }^{3}$ Professores do Departamento de Fitotecnia da Universidade Federal de Viçosa - UFV, 36571-000 Viçosa-MG.

Planta Daninha, Viçosa-MG, v.19, n.2, p.229-234, 2001 


\section{INTRODUÇÃO}

Entre os fatores que interferem na produção da cultura da soja estão as plantas daninhas, que competem por água, luz, nutriente e espaço, reduzindo a produtividade e aumentando o custo de produção. Estas plantas prejudicam ainda as operações de colheita, causando perdas e contaminações, reduzindo a qualidade e depreciando o produto colhido (Silva et al., 2000).

A integração dos métodos químico e cultural no controle das plantas daninhas pode se constituir numa recomendação adequada para reduzir as doses dos herbicidas. O controle cultural consiste no aproveitamento das próprias características agronômicas das plantas cultivadas e daninhas, de forma que a primeira se beneficie da convivência. Isto pode ser obtido, por exemplo, com distribuição adequada de plantas de soja na área de cultivo, promovendo a rápida cobertura do solo pela cultura. No Brasil, a semeadura da soja é recomendada, de maneira geral, em espaçamentos de 40 a $60 \mathrm{~cm}$ entre linhas e com densidade de 16 a 24 plantas por metro, variando em função da variedade e fertilidade do solo. Diversas pesquisas estão evidenciando que espaçamentos menores, mantendo as mesmas populações de plantas por unidade de área, propiciam maiores rendimentos, devido ao aproveitamento mais eficiente da radiação solar, da água e dos nutrientes, além da menor interferência das plantas daninhas como conseqüência do fechamento mais rápido do dossel vegetativo (Carvalho, 1993; Brizuela, 1994; Braz, 1996). Essa cobertura mais rápida do solo pela cultura pode reduzir as doses dos herbicidas e/ou o número de capinas para o controle das plantas daninhas (Rassini \& Durigan, 1988).

Dessa forma, procurou-se avaliar os efeitos da combinação de espaçamentos entre fileiras associados a épocas de aplicação e doses do herbicida imazamox sobre o manejo de plantas daninhas e a produtividade da cultura da soja.

\section{MATERIAL E MÉTODOS}

O experimento foi conduzido no período de 4/12/97 a 14/4/98, num solo de textura franco-argilo-arenosa, no município de Coimbra-MG.
Foram avaliados 16 tratamentos em quatro repetições, num delineamento experimental de blocos ao acaso, dispostos num esquema fatorial $2 \times 8$. O primeiro fator correspondeu aos espaçamentos entre fileiras (30 e $60 \mathrm{~cm}$ ), e o segundo, aos modos de aplicação (aplicação única de imazamox nas doses de 30 e 40 g i.a. ha-1, nas etapas precoce e padrão; aplicação seqüencial de imazamox nas doses de $15+15$ e $20+$ $20 \mathrm{~g}$ i.a. ha ${ }^{-1}$ sendo a primeira na época precoce e a segunda na época padrão; testemunha com capina; e testemunha sem capina). As parcelas tinham quatro metros de comprimento e espaçamento entre fileiras de 30 e $60 \mathrm{~cm}$, sendo constituídas por 14 e 7 fileiras, respectivamente. A área total de cada parcela era de $16,8 \mathrm{~m}^{2}$, sendo considerados como área útil $5,4 \mathrm{~m}^{2}$ (3 $\mathrm{m}$ de comprimento e seis ou três fileiras centrais, dependendo do espaçamento entre fileiras - 30 ou $60 \mathrm{~cm}$ ).

O preparo do solo constou de uma aração e duas gradagens um mês antes da instalação do experimento. Por ocasião da semeadura, foi realizada adubação, no sulco, com $500 \mathrm{~kg} \mathrm{ha}^{-1}$ da formulação 4-14-8. Após a mistura do adubo com o solo no sulco, fez-se a semeadura, em profundidade média de $3 \mathrm{~cm}$. O cultivar utilizado foi o UFV-16, semeado manualmente, distribuindo-se 18 e 36 sementes por metro de sulco, espaçados de 30 e $60 \mathrm{~cm}$, respectivamente. Após o desbaste foram deixadas 12 e 24 plantas por metro de fileira, com espaçamento de $30 \mathrm{e}$ $60 \mathrm{~cm}$, respectivamente, obtendo-se uma população estimada de 400.000 plantas ha ${ }^{-1}$.

As épocas de aplicação do imazamox foram: pós-emergência precoce (13 dias após a semeadura-DAS) e pós-emergência-padrão (24 DAS). Na pós-emergência precoce as plantas de soja estavam no estádio V1, segundo escala de Fehr et al. (1971), e as plantas daninhas mono e dicotiledôneas, respectivamente com um perfilho e um primeiro par de folhas, em média. Na pós-emergência-padrão, a soja estava no estádio V3, e as plantas daninhas mono e dicotiledôneas, respectivamente com três perfilhos e três pares de folhas em média.

As aplicações foram realizadas com pulverizador costal, pressurizado a $\mathrm{CO}_{2}$, munido de uma barra com quatro bicos tipo leque 110-03vs, espaçados de $50 \mathrm{~cm}$, calibrado para uma pressão de $30 \mathrm{lb} \mathrm{pol}^{-2}$ e volume de calda 
de $200 \mathrm{~L} \mathrm{ha}^{-1}$. Em todos os tratamentos com imazamox adicionou-se à calda o surfatante não-iônico Cicol (nonil-senol-etoxilado) a $0,125 \% \mathrm{v} / \mathrm{v}$.

A avaliação da eficácia dos tratamentos no controle das plantas daninhas em relação à testemunha sem capina foi feita visualmente aos 58 DAS, de acordo com a escala da Asociación Latinoamericana de Malezas (ALAM, 1974).

A altura das plantas de soja e a de inserção da primeira vagem (média de cinco plantas/ parcela) foram avaliadas no momento da colheita, a qual foi realizada na área útil das parcelas, quando a soja atingiu o estádio R8, segundo escala de Fehr et al. (1971). A colheita foi realizada de forma manual, sendo a debulha feita em trilhadeira própria para parcelas experimentais. O peso de 100 sementes foi obtido pela contagem e pesagem de uma amostra retirada do total de grãos colhidos por parcela.

Fez-se a análise de variância para alturas de planta e de inserção da primeira vagem, peso de 100 sementes e produtividade. Os resultados obtidos na avaliação da porcentagem de controle das plantas daninhas não apresentaram distribuição normal, segundo o teste de Lilliefors (Demétrio, 1978), motivo pelo qual não foram submetidos à análise de variância, sendo expressos em porcentagem em relação à testemunha sem capina.

\section{RESULTADOS E DISCUSSÃO}

As espécies Galinsoga parviflora, Bidens pilosa, Blainvillea rhomboidea, Ipomoea grandifolia (Tabela 1) e Digitaria horizontalis (Tabela 2) tiveram controle considerado muito bom a ótimo $(\geq 81 \%)$ para todos os tratamentos com imazamox, independentemente de espaçamento da cultura, dose e época de aplicação. Para Acanthospermum hispidum e Brachiaria plantaginea (Tabela 2), o imazamox proporcionou controle ótimo $(\geq 91 \%)$ nos espaçamentos, nas épocas de aplicação e nas doses avaliadas.

Como, praticamente, não houve diferença no controle das plantas daninhas entre as doses de imazamox avaliadas, pode-se recomendar para essas espécies a dose de $30 \mathrm{~g} \mathrm{ha}^{-1} \mathrm{de}$ imazamox, com a aplicação podendo ser realizada nas épocas precoce (13 DAS) ou padrão (24 DAS). Marochi (1993) verificou que, em aplicações de herbicidas em semeadura direta sobre plantas daninhas dicotiledôneas com duas a quatro folhas e monocotiledôneas com dois a três perfilhos, a dose reduzida de herbicida pode proporcionar ótimo controle $(\geq 91 \%)$ das plantas daninhas, até mesmo em área de alta infestação destas, quando comparada a plantas daninhas em estádios mais avançados.

Tabela 1 - Médias da porcentagem de controle de Galinsoga parviflora, Bidens pilosa, Blainvillea rhomboidea e Ipomoea grandifolia aos 58 DAS nos diferentes modos de controle de imazamox, nos espaçamentos de 30 e $60 \mathrm{~cm}$. Viçosa-MG, 1998

\begin{tabular}{|c|c|c|c|c|c|c|c|c|c|c|c|c|c|}
\hline \multirow{2}{*}{\multicolumn{2}{|c|}{ Modos de controle }} & \multicolumn{3}{|c|}{ G. parviflora } & \multicolumn{3}{|c|}{ B. pilosa } & \multicolumn{3}{|c|}{ B. rhomboidea } & \multicolumn{3}{|c|}{ I. grandifolia } \\
\hline & & \multicolumn{2}{|c|}{$\begin{array}{c}\text { Espaçamento } \\
(\mathrm{cm})\end{array}$} & \multirow{2}{*}{ Média } & \multicolumn{2}{|c|}{$\begin{array}{l}\text { Espaçamento } \\
(\mathrm{cm})\end{array}$} & \multirow{2}{*}{ Média } & \multicolumn{2}{|c|}{$\begin{array}{l}\text { Espaçamento } \\
(\mathrm{cm})\end{array}$} & \multirow{2}{*}{ Média } & \multicolumn{2}{|c|}{$\begin{array}{l}\text { Espaçamento } \\
(\mathrm{cm})\end{array}$} & \multirow{2}{*}{ Média } \\
\hline $\begin{array}{l}\text { Imazamox } \\
\left(\text { g i.a. } \text { ha }^{-1}\right)\end{array}$ & Épocas & 30 & 60 & & 30 & 60 & & 30 & 60 & & 30 & 60 & \\
\hline 40 & Precoce & 99 & 97 & 98,0 & 99 & 93 & 96,0 & 92 & 92 & 92,0 & 92 & 90 & 91,0 \\
\hline 40 & Padrão & 95 & 96 & 95,5 & 93 & 91 & 92,0 & 91 & 87 & 89,0 & 93 & 94 & 93,5 \\
\hline 30 & Precoce & 100 & 99 & 99,5 & 100 & 93 & 96,5 & 93 & 87 & 90,0 & 95 & 86 & 90,5 \\
\hline 30 & Padrão & 95 & 93 & 94,0 & 90 & 87 & 88,5 & 90 & 81 & 85,5 & 97 & 93 & 95,0 \\
\hline $20+20$ & Precoce+Padrão & 98 & 95 & 96,5 & 94 & 88 & 91,0 & 82 & 92 & 87,0 & 97 & 90 & 93,5 \\
\hline $15+15$ & Precoce+Padrão & 98 & 96 & 97,0 & 93 & 96 & 93,0 & 85 & 88 & 86,5 & 93 & 92 & 92,5 \\
\hline \multicolumn{2}{|c|}{ Média } & 97,5 & 96,0 & - & 94,8 & 91,3 & - & 88,8 & 87,8 & - & 94,5 & 90,8 & - \\
\hline
\end{tabular}

Conceitos de controle, segundo escala da ALAM (1974): muito ruim (0-40\%); ruim (41-60\%); regular (61-70\%); bom (71-80\%); muito bom (81-90\%); ótimo (91-100\%). 
Tabela 2 - Médias da porcentagem de controle de Acanthospermum hispidum, Digitaria horizontalis e Brachiaria plantaginea aos 58 DAS nos diferentes modos de controle de imazamox, nos espaçamentos de 30 e $60 \mathrm{~cm}$. Viçosa-MG, 1998

\begin{tabular}{|c|c|c|c|c|c|c|c|c|c|c|}
\hline \multirow{2}{*}{\multicolumn{2}{|c|}{ Modos de controle }} & \multicolumn{3}{|c|}{ A. hispidum } & \multicolumn{3}{|c|}{ D. horizontalis } & \multicolumn{3}{|c|}{ B. plantaginea } \\
\hline & & \multicolumn{2}{|c|}{$\begin{array}{l}\text { Espaçamento } \\
(\mathrm{cm})\end{array}$} & \multirow{2}{*}{ Média } & \multicolumn{2}{|c|}{$\begin{array}{l}\text { Espaçamento } \\
(\mathrm{cm})\end{array}$} & \multirow{2}{*}{ Média } & \multicolumn{2}{|c|}{$\begin{array}{l}\text { Espaçamento } \\
(\mathrm{cm})\end{array}$} & \multirow{2}{*}{ Média } \\
\hline $\begin{array}{l}\text { Imazamox } \\
\left(\mathrm{g} \mathrm{i.a.ha}^{-1}\right)\end{array}$ & Épocas & 30 & 60 & & 30 & 60 & & 30 & 60 & \\
\hline 40 & Precoce & 100 & 100 & 100,0 & 99 & 94 & 96,5 & 100 & 94 & 97,0 \\
\hline 40 & Padrão & 100 & 100 & 100,0 & 88 & 81 & 84,5 & 100 & 100 & 100,0 \\
\hline 30 & Precoce & 100 & 100 & 100,0 & 100 & 92 & 96,0 & 100 & 100 & 100,0 \\
\hline 30 & Padrão & 100 & 100 & 100,0 & 86 & 87 & 86,5 & 100 & 100 & 100,0 \\
\hline $20+20$ & Precoce+Padrão & 100 & 100 & 100,0 & 92 & 88 & 90,0 & 100 & 100 & 100,0 \\
\hline $15+15$ & Precoce+Padrão & 100 & 100 & 100,0 & 95 & 92 & 93,5 & 100 & 100 & 100,0 \\
\hline \multicolumn{2}{|c|}{ Média } & 100,0 & 100,0 & - & 93,3 & 89,0 & - & 100,0 & 99,0 & - \\
\hline
\end{tabular}

Conceitos de controle, segundo escala da ALAM (1974): muito ruim (0-40\%); ruim (41-60\%); regular (61-70\%); bom (71-80\%); muito bom (81-90\%); ótimo (91-100\%).

Tabela 3 - Médias das alturas de plantas e inserção da primeira vagem e do peso de 100 sementes nos diferentes modos de controle do imazamox, nos espaçamentos de 30 e $60 \mathrm{~cm}$. Viçosa-MG, 1998

\begin{tabular}{|c|c|c|c|c|c|c|c|c|c|c|}
\hline \multirow{2}{*}{\multicolumn{2}{|c|}{ Modos de controle }} & \multicolumn{3}{|c|}{ Altura de Plantas ${ }^{1 /}(\mathrm{cm})$} & \multicolumn{3}{|c|}{ Inserção da $1^{\text {a }} \operatorname{Vagem}^{2 /}(\mathrm{cm})$} & \multicolumn{3}{|c|}{ Peso de 100 Sementes $^{2 /}(\mathrm{g})$} \\
\hline & & \multicolumn{2}{|c|}{$\begin{array}{c}\text { Espaçamento } \\
(\mathrm{cm})\end{array}$} & \multirow{2}{*}{ Média } & \multicolumn{2}{|c|}{$\begin{array}{c}\text { Espaçamento } \\
(\mathrm{cm})\end{array}$} & \multirow{2}{*}{ Média } & \multicolumn{2}{|c|}{$\begin{array}{c}\text { Espaçamento } \\
(\mathrm{cm})\end{array}$} & \multirow{2}{*}{ Média } \\
\hline $\begin{array}{l}\text { Imazamox } \\
\left(\mathrm{g} \text { i.a. } \mathrm{ha}^{-1}\right)\end{array}$ & Épocas & 30 & 60 & & 30 & 60 & & 30 & 60 & \\
\hline 40 & Precoce & 93 & 87 & 90,0 & 13 & 16 & 14,5 & 17 & 15 & 16,0 \\
\hline 40 & Padrão & 93 & 92 & 92,5 & 16 & 16 & 16,0 & 15 & 16 & 15,5 \\
\hline 30 & Precoce & 89 & 90 & 89,5 & 14 & 16 & 15,0 & 16 & 15 & 15,5 \\
\hline 30 & Padrão & 96 & 92 & 94,0 & 17 & 16 & 16,5 & 15 & 15 & 15,0 \\
\hline $20+20$ & Precoce + Padrão & 87 & 92 & 89,5 & 16 & 15 & 15,5 & 16 & 15 & 15,5 \\
\hline $15+15$ & Precoce + Padrão & 86 & 90 & 88,0 & 17 & 18 & 17,5 & 16 & 16 & 16,0 \\
\hline Test. c/ capinas & - & 97 & 96 & 96,5 & 16 & 17 & 16,5 & 17 & 16 & 16,5 \\
\hline Test. s/ capina & - & 92 & 94 & 93,0 & 14 & 16 & 15,0 & 15 & 15 & 15,0 \\
\hline \multicolumn{2}{|c|}{ Média } & 91,6 & 91,6 & - & 15,4 & 16,3 & - & 15,9 & 15,4 & - \\
\hline \multicolumn{2}{|c|}{$\mathrm{CV}$} & \multicolumn{3}{|c|}{5,3} & \multicolumn{3}{|c|}{19,9} & \multicolumn{3}{|c|}{5,4} \\
\hline
\end{tabular}

${ }^{1}$ Significativo pelo teste $\mathrm{F}$ a $5 \%$ de probabilidade, porém não-significativo pelo teste de Tukey a 5\% de probabilidade.

2/ Não-significativo pelo teste $\mathrm{F}$.

Os efeitos dos tratamentos sobre as características agronômicas da soja avaliadas (altura de plantas e de inserção da primeira vagem e peso de 100 sementes) estão apresentados na Tabela 3. Não houve diferença significativa entre os tratamentos, pelo teste de Tukey a $5 \%$ de probabilidade. Estes resultados confirmam a alta seletividade do imazamox para a cultura da soja. Osipe et al. (1997) e Zagonel (1997) observaram resultados semelhantes. 
Tabela 4 - Médias da produtividade da cultura e porcentagem em relação às testemunhas com capina. Viçosa-MG, 1998

\begin{tabular}{|c|c|c|c|c|c|c|c|}
\hline \multirow{2}{*}{\multicolumn{2}{|c|}{ Modos de controle }} & \multicolumn{6}{|c|}{ Produtividade $^{-1 /}$} \\
\hline & & \multicolumn{3}{|c|}{$\left(\mathrm{kg} \mathrm{ha}^{-1}\right)$} & \multicolumn{3}{|c|}{ \% relação à test. c/ capina } \\
\hline $\begin{array}{c}\text { Imazamox } \\
\left(\mathrm{g} \text { i.a. } \mathrm{ha}^{-1}\right)\end{array}$ & Época & $30 \mathrm{~cm}$ & $60 \mathrm{~cm}$ & Média & $30 \mathrm{~cm}$ & $60 \mathrm{~cm}$ & Média \\
\hline 40 & Precoce & 2.360 & 2.129 & $2.244,5$ & 100 & 82 & 91,0 \\
\hline 40 & Padrão & 2.142 & 2.290 & $2.216,0$ & 91 & 88 & 89,5 \\
\hline 30 & Precoce & 2.229 & 2.128 & $2.178,5$ & 94 & 82 & 88,0 \\
\hline 30 & Padrão & 2.112 & 2.148 & $2.130,0$ & 90 & 83 & 86,5 \\
\hline $20+20$ & Precoce + Padrão & 2.401 & 2.179 & $2.290,0$ & 101 & 84 & 92,5 \\
\hline $15+15$ & Precoce + Padrão & 2.154 & 2.235 & $2.194,5$ & 91 & 86 & 88,5 \\
\hline Test. Capinada & - & 2.358 & 2.593 & $2.475,5$ & 100 & 100 & 100,0 \\
\hline Test. s/ capina & - & 1.560 & 1.626 & $1.593,0$ & 66 & 63 & 64,5 \\
\hline \multicolumn{2}{|c|}{ Média } & $2.164,5$ & $2.166,0$ & - & 91,6 & 83,5 & - \\
\hline \multicolumn{2}{|c|}{$\mathrm{CV}$} & \multicolumn{3}{|c|}{20,5} & & & \\
\hline
\end{tabular}

1/ Não-significativo pelo teste $\mathrm{F}$ a $10 \%$ de probabilidade.

Considerando a média da produção de grãos nos tratamentos, não houve diferença entre os espaçamentos de 30 e $60 \mathrm{~cm}$, assim como não houve diferenças entre doses de imazamox e entre as épocas de aplicação (Tabela 4). Comparando as testemunhas sem capina com as capinadas nos dois espaçamentos, verifica-se redução na produtividade de 34 e 37\%, para os espaçamentos de 30 e $60 \mathrm{~cm}$, respectivamente, indicando que houve interferência das plantas daninhas, mas que o espaçamento pouco influenciou. Segundo Marochi (1993), as perdas no rendimento de soja ocasionadas por plantas daninhas estão relacionadas a local de ocorrência (linha ou entrelinha), período de convivência, umidade do solo e, principalmente, densidade de infestação, verificando-se maiores perdas em condições de maior espaçamento da cultura.

Quanto ao controle das plantas daninhas, observou-se, nas avaliações visuais, que o imazamox apresentou eficiência de controle variável, de muito boa a ótima $(\geq 81 \%)$, não sendo esperadas, portanto, diferenças na produtividade em relação a espaçamentos, épocas de aplicação e doses do imazamox, uma vez que este não causou toxicidade à cultura.

O imazamox tem potencial para ser usado no manejo das plantas daninhas na cultura da soja em aplicação única ou parcelada, nas épocas precoce ou padrão.

\section{LITERATURA CITADA}

ASOCIACIÓN LATINOAMERICANA DE MALEZAS. Recomendaciones sobre unificación de los sistemas de evaluacion en ensayos de control de malezas. ALAM, v.1, n.1, p.35-38, 1974.

BRAZ, B.A. Efeitos de reduções de distâncias entrelinhas e de dosagens de latifolicidas no controle de plantas daninhas na cultura da soja (Glycine max (L.) Merrill). Jaboticabal: UNESP, 1996. 143p. Tese (Doutorado em Produção Vegetal) - Universidade Estadual Paulista, 1996.

BRIZUELA, S.F.B. Efeito de variedades, espaçamentos e doses de herbicidas nas relações de interferência entre a cultura da soja e a comunidade infestante. Jaboticabal: UNESP, 1994. 112p. Dissertação (Mestrado em Agronomia) Universidade Estadual Paulista, 1994.

CARVALHO, F.T. Integração de práticas culturais e dosagens de herbicida aplicado em pósemergência, no controle de plantas daninhas e produtividade da cultura da soja (Glycine $\max ($ L. ) Merr.). Jaboticabal: UNESP, 1993. 94p. Dissertação (Mestrado em Agronomia) Universidade Estadual Paulista, 1993. 
DEMÉTRIO, C.G.B. Transformação de dados. Efeitos sobre a análise da variância. Piracicaba: ESALQ, 1978. 113p. Dissertação (Mestrado em Experimentação e Estatística) - Escola Superior de Agricultura “Luiz de Queiroz”, 1978.

FEHR, W.R.; CAVINESS, C.E.; BURMOOD, D.T.; PENNIGTON, J.S. Stage of development descriptions for soybeans, Glycine $\max (\mathrm{L}$.$) Merril.$ Crop. Sci., v.11, p.929-931, 1971.

MAROCHI, A.I. Controle de infestantes na cultura da soja. R. Batavo, v.2, n.25, p.18-26, 1993.

OSIPE, R.; NISHIMURA, M.; LOPES, D. Avaliação da eficiência e seletividade de herbicidas aplicados em misturas de tanque, em pósemergência na cultura da soja. In: CONGRESSO BRASILEIRO DA CIENCIA DAS PLANTAS DANINHAS, 21, 1997, Caxambu. Resumos... Caxambu: SBHED, 1997. p.115.
RASSINI, J. B.; DURIGAN, J.C. Práticas culturais e uso de baixas dosagens de herbicidas em pósemergência, para o controle de plantas daninhas na cultura da soja (Glycine max). I. Efeitos do desenvolvimento da cultura no controle das plantas daninhas. In: CONGRESSO BRASILEIRO DE HERBICIDAS E PLANTAS DANINHAS, 17, 1988, Piracicaba. Resumos... Piracicaba: SBHED, 1988. p.167-9.

SILVA, A.A.; SILVA, J.F.; FERREIRA, F.A.; FERREIRA, L.R.; SILVA, J.F.; OLIVEIRA JUNIOR, R.S; VARGAS, L. Controle de plantas daninhas In: ASSOCIAÇÃO BRASILEIRA DE EDUCAÇÃO SUPERIOR. Brasília: ABEAS, 2000.

ZAGONEL, J. Controle de plantas daninhas na cultura da soja com oxasulfuron e as misturas oxasulfuron + imazethapyr e oxasulfuron + imazamox. In: CONGRESSO BRASILEIRO DA CIÊNCIA DAS PLANTAS DANINHAS, 21, 1997, Caxambu. Resumos... Caxambu: SBHED, 1997. p. 142 . 